\title{
Rare case of Ectopic ACTH secreting tumour causing cyclical Cushing's syndrome
}

\section{ECE 2015 Case reports Adrenal-EP55}

\author{
J.Acharya, S Akavarapu,P.Valsalakumari, ,A.Abbara and JF Todd
}

Department of Endocrinology ,Hammersmith Hospital, Imperial collage healthcare NHS trust, London ,UK

\section{Introduction}

Cyclical Cushings syndrome is a rare disorder characterised by the episodic excess cortisol secretion and normal cortisol secretion in between. It is associated with fluctuating symptoms and signs.. Pituitary Corticotroph adenoma is the most common cause of Cyclical Cushings syndrome accounting more than $50 \%$ of patients. Around $26 \%$ caused by Ectopic ACTH secreting adenomas and $11 \%$ from the adrenal tumours and remainders unknown. (1)

\section{Case report}

63 year old lady presented with severe myopathy, easy bruisability and weight gain. She had elevated ACTH of $610 \mathrm{mU} / \mathrm{L}$ and midnight cortisol of $1710 \mathrm{nmol} / \mathrm{L}$. Diagnosis of ACTH dependent Cushing syndrome was made. Her MRI pituitary was normal. Inferior petrosal venous sinsus sampling test were not confirmative but suggested possible pituitary source. Her symptoms improved after Metyrapone.

Her cortisol levels started dropping 2 months later and she was weaned off Metyrapone and discharged home once she was symptom free.

She re-presented 4 months later with similar symptoms midnight cortisol of $1400 \mathrm{nmol} / \mathrm{L}$ and ACTH $413 \mathrm{mU} / \mathrm{L}$. She underwent Gallium DOTATATE scan showed rt lower lobe gallium avid lesion. Repeat IPSS did not show confirmed ectopic source. She underwent surgical excision 8 months later with histology confirms neuroendocrine tumour Ki67 index less than 3\% and she needed hydrocortisone post operatively
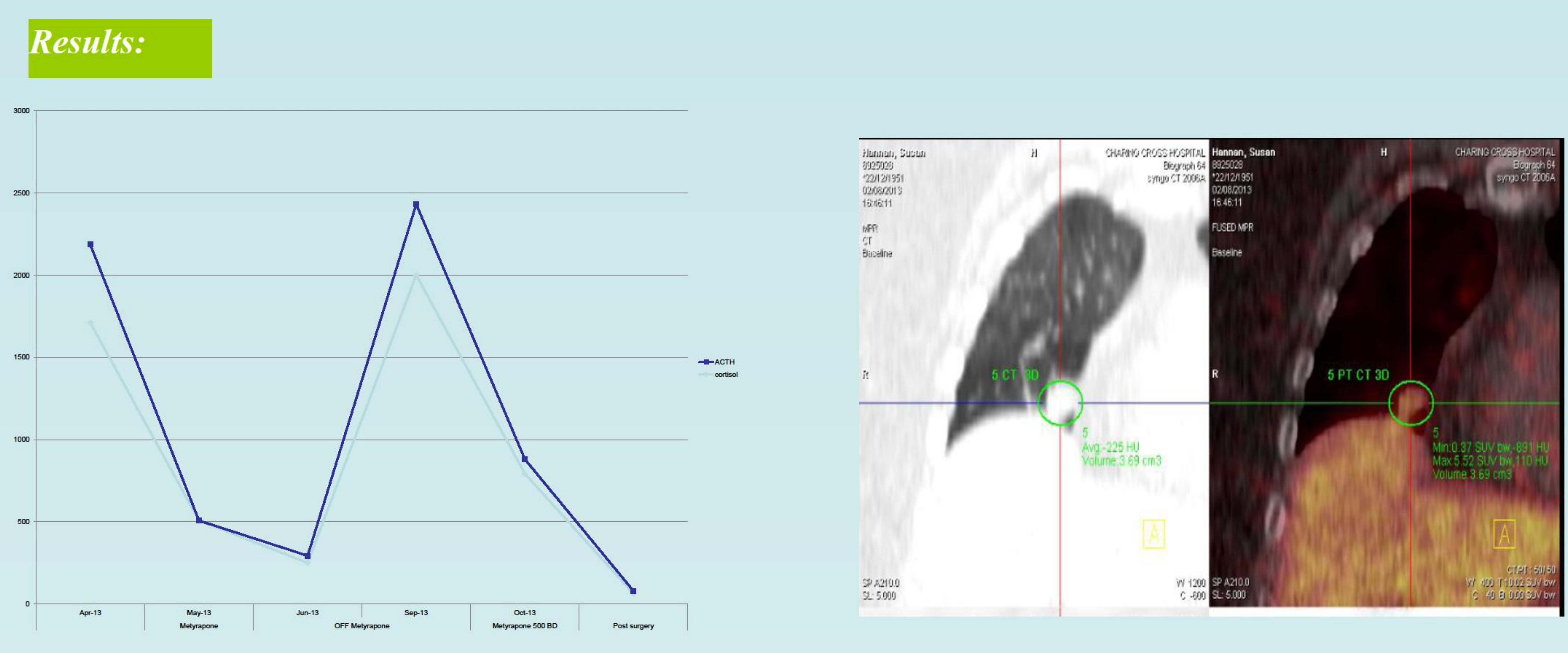

\section{Conclusions:}

Cyclical Cushing's syndrome due Ectopic ACTH is extremely difficult to diagnose due to fluctuating clinical picture and biochemistry. In suspected cases specific biochemical and imaging investigation for neuroendocrine tumour is required. Gallium DOTATE scan is more sensitive in localising these tumours

\section{References:}

Cyclical Cushing's syndrome ;a clinical challenge Meinardi..et Eur J endocrinology .2007 157(3) 245 